\title{
Latex allergy in health care workers: prevalence and knowledge at a tertiary teaching hospital in a developing country
}

\author{
Nazir Ahmed Ismail 1 , Anwar Ahmed Hoosen ${ }^{1}$, Shaheen Mehtar ${ }^{2}$ \\ ${ }^{1}$ Department of Medical Microbiology, University of Pretoria \\ ${ }^{2}$ Academic Unit for Infection Prevention \& Control - Tygerberg Hospital, University of Stellenbosch \\ doi: 10.3396/ijic.V6i1.004.10
}

\begin{abstract}
Latex allergy is an important concern from an occupational safety aspect and affects compliance of glove usage, which directly influences infection control practices aimed at providing safe medical care for both the health care worker (HCW) and patient.
\end{abstract}

The Dr George Mukhari Hospital (DGM) in Pretoria has a staff complement of 1500 doctors and nurses who use latex gloves occasionally or regularly. The objective for this study was to evaluate the current prevalence of latex allergies and staff awareness of latex glove allergies as well as the availability of alternatives. Occupational health and laboratory records were reviewed for evidence of latex allergy and a crude rate of $4 \%$ was determined in this study population over the study period. Interviews assessing HCW knowledge and practices regarding latex glove allergy and alternatives were performed using a questionnaire. Results from the interviews identified numerous gaps in knowledge regarding latex allergies and alternatives even amongst those who had latex allergies.

Thus greater efforts are required to educate HCWs regarding latex allergies and consideration should be given to the use of non-latex gloves in high use areas to reduce future latex allergy development which can affect the HCW's occupational and social functioning.

\section{Corresponding author}

Dr N.A. Ismail, Room 3-22, Department of Medical Microbiology, Institute of Pathology,

Prinshof Campus University of Pretoria, 0001, South Africa

Tel: +27-12-319-2252, Fax: +27-12-3192126, Cell: +27-79-526-8060, Email: nazir.ismail@gmail.com 


\section{Introduction}

Latex allergy is an important concern from an occupational safety aspect and affects compliance with glove usage, which directly influences infection control practices aimed at providing safe medical care for both the health care worker (HCW) and patient. Evidence of the use of latex items dates back to 1600 BC. ${ }^{1}$ However, their use in the manufacture of gloves has only been since the early 1900s and the earliest record of an allergic reaction to these products was in 1927. ${ }^{2}$ There has been an increased incidence of latex allergies since the 1980s, which coincided with the beginning of the human immunodeficiency virus/ acquired immunodeficiency syndrome epidemic and the subsequent increasing use of gloves during patient contact. $^{3}$

Three types of latex reactions are observed on the skin: irritant contact dermatitis with dry itchy skin, allergic contact dermatitis (type 4 hypersensitivity) and latex allergy due to a type 1 hypersensitivity reaction. ${ }^{4}$ These reactions are attributed to a variety of proteins found in natural rubber latex ${ }^{5}$ as well as chemicals and additives including powders. ${ }^{6}$ Common manifestations of latex allergy are skin reactions, however aerosolization has also been recognized as the cause of allergic rhinitis and asthma especially in HCW. ${ }^{7}$ Less commonly recognized reactions are the association between latex allergy and allergies to a variety of fruits and nuts. ${ }^{8}$

The diagnosis of latex allergy is based on history, a serological test for antibodies to latex antigens and skin prick testing. ${ }^{9}$ However, low sensitivities of these tests mean that negative results do not exclude latex allergy. ${ }^{10}$ Possible reasons for this finding relate to the variety of latex proteins involved, as well as the nonlatex components of the gloves. ${ }^{6}$ Thus a diagnosis of latex allergy is strongly dependent on a good history including new onset allergies to fruits and nuts.

The impact of latex allergy for health care personnel is far reaching and a study conducted in the United Kingdom showed that for some it resulted in a change in the nature of their jobs. For others, upon a visit to their doctor or dentist they were met with ill-informed staff and had to bring their own gloves as patients and, lastly, dietary changes became necessary. ${ }^{11}$
The Dr George Mukhari Hospital (DGM) has a staff complement of 1500 doctors and nurses who use latex gloves occasionally or regularly. The objectives for this study were to determine the number of staff members who had latex allergies and secondly to evaluate staff awareness of latex glove allergies as well as knowledge of alternatives available at the DGM.

\section{Methods}

An analysis was performed of latex allergy cases reported to Occupational Health officers as well as laboratory data of latex allergy testing performed on staff at the DGM from the beginning of January 2004 till the end of November 2005. All healthcare professionals present in all the high care wards of the hospital on a particular day were interviewed. The questionnaire included questions on glove usage practice, latex allergy awareness and knowledge of available alternatives. This selection of the study population was made on the basis of high usage of gloves in these areas of the hospital. The data were then analyzed.

\section{Results}

During the period 1 January 2004 and 30 November 2005, $63(4.2 \%)$ of $1500 \mathrm{HCWs}$ presented with symptoms suggestive of latex allergy and were tested for antibodies to latex antigen - Hevea brasiliensis (k82, ImmunoCAP, Sweden). Fourteen of the 63(22\%) tested positive for latex IgE. Three of these were working in casualty, two in the medical outpatients department, two in the operating theatres and the rest in various areas of the hospital.

A total of 14 interviews were then carried out with staff working in the high care areas viz.: Neonatal intensive care unit (ICU), Surgical ICU, Cardio-thoracic ICU, Renal Unit, Renal Transplant Unit and the Neurosurgery ward. Five of the interviewees were registrars (physicians) in training, one was a consultant working in the renal unit and eight were professional nurses. Of these, four reported having an allergy to latex, three others reported allergy to powder in the gloves and two reported allergy to chlorhexidine. 
The interview evaluated glove selection for various common procedures performed (Table I). Only 1 of 6 doctors and 3 of 8 nurses opted to use sterile gloves for an IV line insertion. Additionally 5 respondents did not distinguish type of glove and activity. Two of the ten non-latex allergy subjects chose not to wear gloves compared to all the subjects $(\mathrm{N}=4)$ with latex allergy who opted to use gloves for the procedure.

When questioned about availability of the correct size of gloves only 4 of the 14 respondents stated that their size was commonly available. All those interviewed were aware of the skin symptoms of latex allergy, however 5 of the 9 did not know of the respiratory symptoms and none of the 14 had any knowledge of the food related allergy. Responses to questions regarding latex items other than gloves in the ward or unit are depicted in Figure 1. When these data were analysed to assess the responses of those with latex allergies, 2 of the 4 could list only one item. Of concern, half of the doctors (3/6) and a quarter of the nurses (2/8) did not know whom to contact in case they suspected they had a latex allergy. Responses regarding available latex glove alternatives are provided in Figure 2.

Table I: Glove selection for activity ( $N=14 ; D=$ Doctors: $N=6 ; N=N$ urses: $N=8)$

\begin{tabular}{|c|c|c|c|c|c|c|c|c|c|c|}
\hline \multirow[b]{2}{*}{ Activity } & \multicolumn{2}{|c|}{ Sterile } & \multicolumn{2}{|c|}{ Non-sterile } & \multicolumn{2}{|c|}{ Any type } & \multicolumn{2}{|c|}{ None } & \multicolumn{2}{|c|}{ No Response } \\
\hline & D & $\mathbf{N}$ & D & $\mathbf{N}$ & D & $\mathbf{N}$ & $\mathbf{D}$ & $\mathbf{N}$ & D & $\mathbf{N}$ \\
\hline IV Line Insertion & 1 & 3 & 1 & 4 & 2 & 1 & 2 & & & \\
\hline Lumbar Puncture & 4 & & & & & & & & 2 & 8 \\
\hline Blood Pressure /Temperature & & & & & & & 6 & 4 & & \\
\hline Handling Soiled Linen & & & 5 & 6 & & 2 & 1 & & & \\
\hline Urine catheterisation & 6 & 6 & & 1 & & & & & & 1 \\
\hline
\end{tabular}

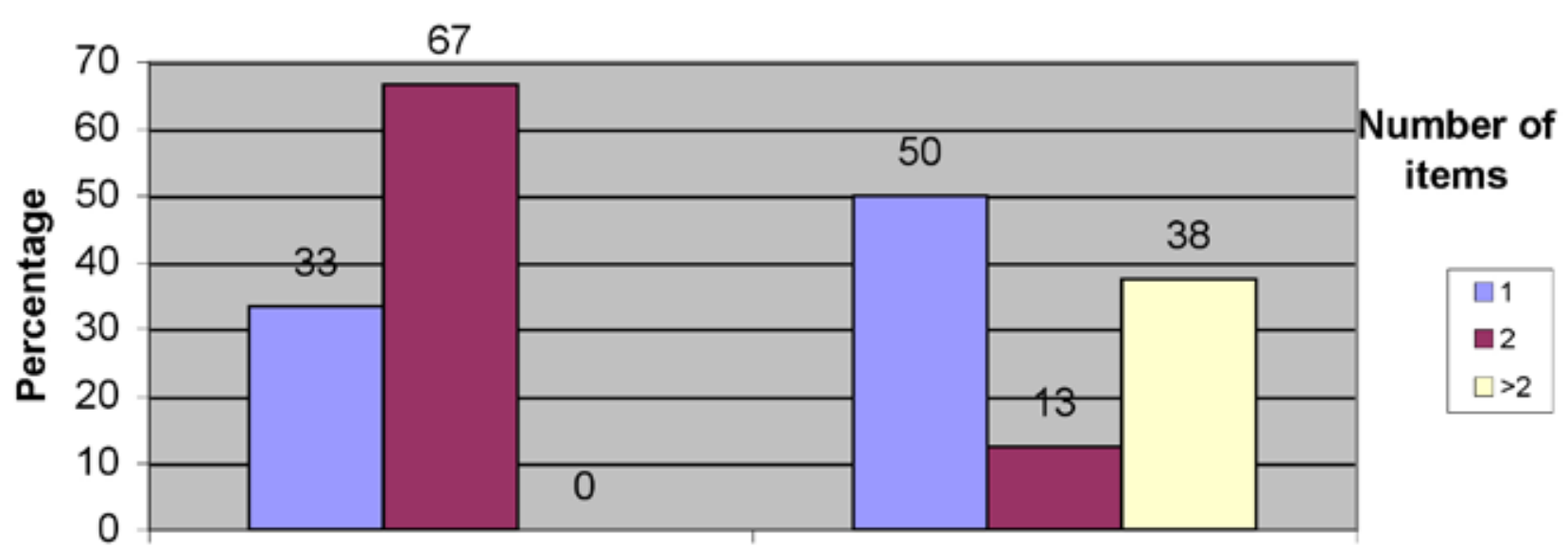

Doctors

Nurses

Category

Figure 1. Staff listing items containing latex other than gloves present in the ward / unit $(\mathrm{N}=14 ; \mathrm{D}=$ Doctors: $\mathrm{N}=6$; $\mathrm{N}=$ Nurses: $\mathrm{N}=8$ ) 


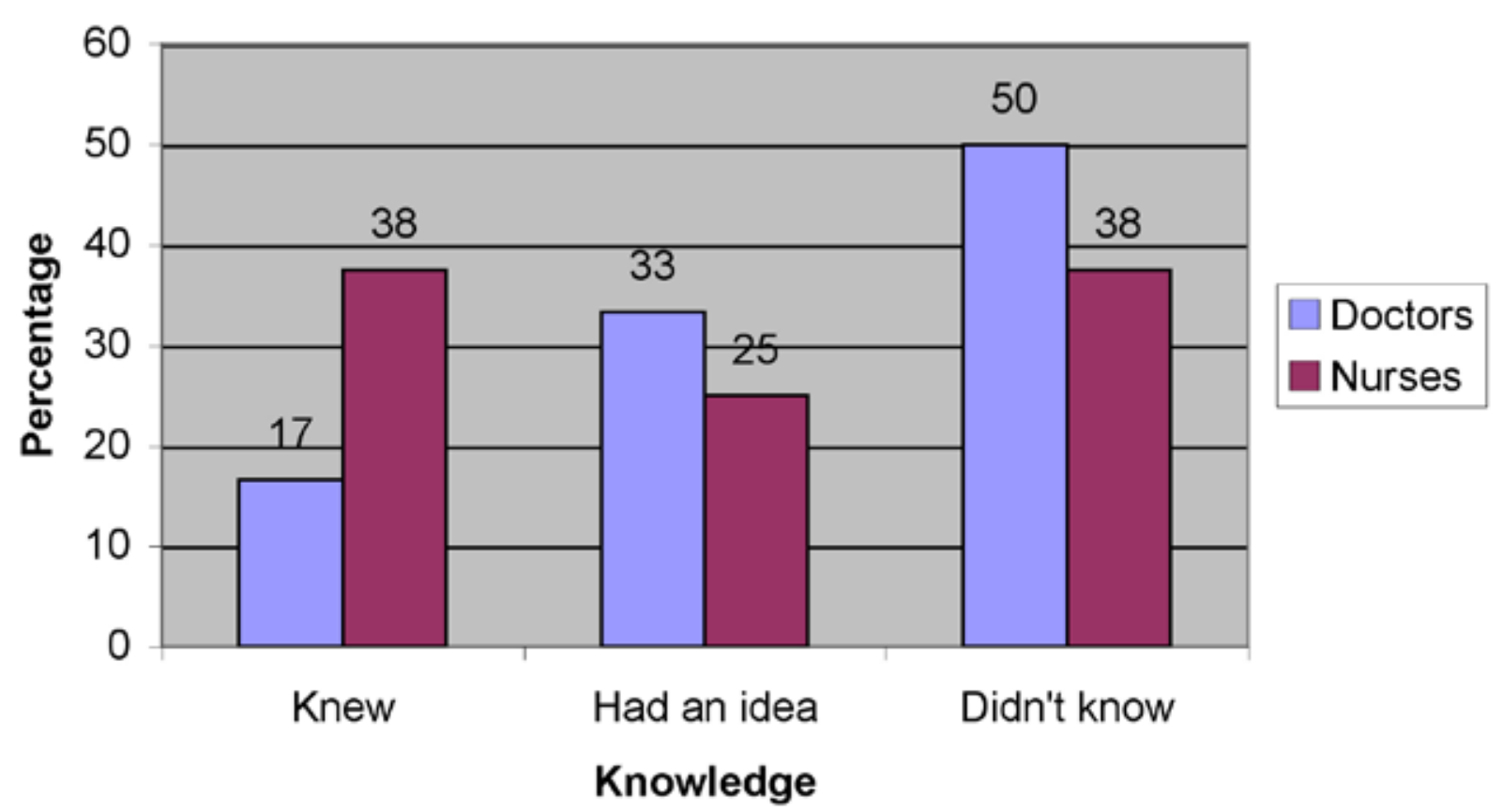

Figure 2. HCW knowledge of glove alternatives for latex allergy $(\mathrm{N}=14)$ - Doctors $(\mathrm{N}=6)$ Nurses $(\mathrm{N}=8)$

\section{Discussion}

The finding of 63 of $1500(4,2 \%)$ HCWs having presented to the Occupational Health facility with allergies to latex over a 2-year period is lower than rates reported from other centers worldwide. ${ }^{3,12,13}$ It should be noted that data from Africa on this subject is scarce. This low rate may be due either to lack of awareness, low latex exposure reflecting poor compliance with standard precautions, or not reporting allergic reactions.

It is noteworthy that only $22 \%$ of those with symptoms had tested positive serologically with the tests used at our institution. It is important to recognize that a negative test does not exclude the diagnosis as latex is composed of numerous proteins and chemical additives, which may be otherwise responsible for allergies. ${ }^{5}$ A clinical evaluation and thorough history should always be conducted to identify the cause. From those interviewed, there was an almost equal number of latex and powder allergy sufferers and also a similar number of chlorhexidine allergic HCWs. Suitable alternatives should nevertheless be provided in the form of either non-latex or powder-free gloves where appropriate. This is vital to ensure compliance with standard precautions.

Those who tested positive were predominantly from areas where glove usage is expected to be high, e.g., casualty and theatre. Long-term regular exposure is known to be a risk factor and this is borne out by the fact that children with spina bifida have a high number of latex allergies reflecting long-term exposure. ${ }^{15,16}$ A reduction in latex allergies has been achieved in Germany and Finland by the decreased use of latex gloves in their institutions. ${ }^{17,18}$ For the local setting, such as in Africa, cost is a limiting factor in introducing such changes and a more prudent option would be to provide these items to high use areas, improving glove usage practices and providing options for those with clinical evidence of latex allergies.

Knowledge regarding latex allergy among those questioned was poor. Although all were aware of skin symptoms, very few knew of other symptoms especially those related to the respiratory and gastro-intestinal 
tracts. Furthermore, half of the doctors and a quarter of the nurses did not know whom to contact in cases where they suspected that they had a latex allergy. Surprisingly, among latex allergy sufferers, only half of them could list more than one latex protein containing item other than gloves in the ward/unit. These findings are clear evidence for a greater need to educate HCWs concerning latex allergies since it is such a common use item. Education has been shown to be an important means of decreasing latex allergies. ${ }^{14}$

Other important findings in this study relate to infection control practice. The first is the availability of the correct size of glove, which was seldom available. The availability of the correct type of glove was noted to be a problem with some staff responding to choice of glove for a specific activity as 'anything that is available'.

Glove selection practices were found to be unsatisfactory for intravenous (IV) line insertion with only $16.7 \%(1 / 6)$ of doctors and $37.5 \%$ (3/8) of nurses opting to use sterile gloves. This is more surprising as all those interviewed were senior health care workers working in high care areas including ICUs. Additionally it was apparent that some HCWs did not differentiate when it came to choosing a sterile versus a non-sterile glove. This could be attributable to availability of the right glove, knowledge or attitude of the HCW. One $\mathrm{HCW}$ preferred not to use gloves for any procedure due to an allergic reaction to latex gloves. This staff member was tested for latex allergy and was negative. This highlights the need for special consideration and management of HCW problems and providing adequate alternatives, otherwise there could be serious failings in infection control practice.

An interesting observation was noted that when the confirmed latex allergy sufferers group was compared with those that did not have latex allergy. Two of those in the non-latex group did not opt to use gloves during the IV line insertion procedure compared to none in the latex allergy group. This could be due to attitude or undetected or false negative laboratory testing that has led to non-compliance. Thus, recognizing and providing the correct alternatives for those with latex allergies may enhance compliance. A limitation of this study is that the study numbers are small and not all 14 interviewees were tested for latex allergies. Further larger studies are warranted to evaluate the role this important factor in compliance with standard precautions.

Latex allergy is an important issue from an occupational safety aspect and does affect compliance, which directly influences infection control practices aimed at providing safe medical care for both the HCW and patient. The use of gloves is a key component of the Centers for Disease Control and Prevention, USA (CDC), Standard Precautions strategy. Therefore, education regarding correct glove selection, awareness of latex allergies and available alternatives is essential. Furthermore, availability of the right types of gloves for $\mathrm{HCW}$, including correct sizes is extremely important for safe infection control practices. Finally, limitation of latex use needs to be considered as a long-term strategy for solving latex allergies among HCWs since it is known that the first symptoms of latex allergy occur on average after five years of exposure. ${ }^{19,20}$ One can surmise that as time passes by the problem may worsen and the need to act is sooner rather than later.

\section{References}

1. Hosler D, Tarkanian MJ. Prehistoric polymers: rubber processing in ancient Mesoamerica. Science. 1999; 284: 1988-1991.

2. Fuch T. Latex allergy. J Allergy Clin Immunol. 1994; 93: 951952.

3. Ownby DR. A history of latex allergy. I Allergy Clin Immunol. 2002; 110(2): S27.

4. Biagini RE, Deitchman S, Esswein EJ et al. NIOSH/latex alert. 1998. DHHS (NIOSH).

5. Sussman GL, Beezhold DH, Kurup VP. Allergens and natural rubber proteins. Journal of Allergy and Clinical Immunology. 2002; 110: S33.

6. Yip E, Cacioli P. The manufacture of gloves from natural rubber latex. Journal of Allergy and Clinical Immunology. 2002; 110(2): S3.

7. Fish JE. Occupational asthma and rhinoconjunctivitis induced by natural rubber latex exposure. Journal of Allergy and Clinical Immunology. 2002; 110: S75.

8. Blanco C, Carrillo T, Castillo R, et al. Latex allergy: clinical features and cross-reactivity with fruits. Ann Allergy. 1994; 73: 309-314.

9. Hamilton RG, Peterson EL, Ownby DR. Clinical and laboratorybased methods in the diagnosis of natural rubber latex allergy. Journal of Allergy and Clinical Immunology. 2002; 110(2): S47.

10. Ollert MW, Merkl J, Ring J. Diagnostic performance of various in vitro assays for specific IgE in adults allergic to natural rubber latex. Journal of Allergy and Clinical Immunology. 2004; 113(Supplement 1): S136. 
11. Lewis VJ, Statham B, Chowdhury M. How does the diagnosis of latex allergy affect people and their lives? Journal of the American Academy of Dermatology. 2004; 50(Supplement 1): 66.

12. Sinha A, Harrison PV. Latex glove allergy among hospital employees: a study in the north-west of England. Occup Med. 1998; 48: 405-410.

13. Liss G. Latex allergy: epidemiological study of 1351 hospital workers. Occup Environ Med. 1997; 54: 335-342.

14. Allmers H, Schmengler J, Skudlik C. Primary prevention of natural rubber latex allergy in the German health care system through education and intervention. Journal of Allergy and Clinical Immunology. 2002; 110(2): 318.

15. Ellsworth PL, Merguerian PA, Klein RB. Evaluation and risk factors of latex allergy in spina bifida patients: Is it preventable? J Urol, 2001; 150: 691-693.

16. Kattan H, Tipirneni P. Latex allergy in Saudi children with spina bifida. Allergy. 1999; 54: 70-73.
17. Allmers $H$, Schmengler J, John SM. Decreasing incidence of occupational contact urticaria caused by natural rubber latex allergy in German health care workers. Journal of Allergy and Clinical Immunology. 2004; 114(2): 347.

18. Reunala T, Turjanmaa $\mathrm{K}$, Alenius $\mathrm{H}$, et al. A significant decrease in the incidence of latex-allergic health care workers parallels with a decreasing percentage of highly allergenic latex gloves in the market in Finland. Journal of Allergy and Clinical Immunology. 2004; 113(Supplement 1): S60.

19. Esterhuizen TM, Rees D. Occurrence and causes of occupational asthma in South Africa-Results from SORDSAS Occupational Asthma Registry, 1997-1999. S Afr Med. 2001; 91: 509-513.

20. Allmers $H$, Kirchner B, Huber $H$, et al. The latency period between exposure and symptoms in allergy to natural latex. Deutche Med Wochen. 1996; 121: 823. 